\title{
Educational potential of medical audit: observations from a study of small groups setting standards
}

\author{
John Newton, Allen Hutchinson, Nick Steen, Ian Russell, Erica Haimes
}

While the main thrust of medical audit has been towards improving clinical performance, there has been increasing recognition of its impact as a method of continuing medical education. Thus, the Royal College of Physicians stated that "education is the most useful product of audit," and the Royal College of Surgeons noted the educational importance of audit "for both seniors and juniors." Furthermore, Batstone suggests that audit can be seen "as a process leading to improved clinical care by mechanisms which may be educational, operational, or both." Coles agrees with these emphases but points out that education (by which he means learning) does not automatically occur just because people go through an audit cycle. Effective learning requires an appropriate and deliberately created set of conditions, among which group based strategies are increasingly important. ${ }^{*}$ As Scott and Marinker stated: "if medical audit is to become an integral part of clinical practice and practice management ... those who take part in it will need from time to time to constitute themselves into formal small groups."

The educational potential of group work has been recognised in medicine and higher education generally. ${ }^{6-8}$ For example, Hull argued that "the special characteristic of the small group is the opportunity it provides for members to examine their own attitudes and modes of thinking." ${ }^{8}$ But the relation between group work and education is not straightforward. For instance, Hull is careful to point out that groups provide the opportunity for learning rather than a guarantee that learning is successful, and Coles warns that education in groups does not simply happen; it has to be organised. ${ }^{4}$ However, even when they are carefully planned, educational initiatives can sometimes fail to result in successful outcomes. As those with experience of working in a group can testify, group process is subject to many influences, not all benign.

The aim of this article is to describe some of the characteristics and the functioning of groups involved in a standard setting process and to comment how the educational potential of collaborative audit is contingent on group processes. The first section describes the educational potential and identifies some of the process factors which may influence its realisation. The second section draws on an observational study of groups setting standards and illustrates how problems arise in groups. The final section discusses the implications of the study's findings for the relation between groups, education, and audit.

\section{Educational potential of group work}

It is one thing to assert that groups are a useful vehicle for achieving educational objectives but another to specify how this might happen. Research by educational psychologists on cooperative learning, however, offers some insights into the processes involved. From an interactional point of view groups enable members to learn from each other. The behaviours which are most conducive to this are giving and receiving help or information, especially in the form of explanations. ${ }^{9}$ From a cognitive point of view it seems that for both givers and receivers the formulation and assimilation of explanations requires people to elaborate or build on what they already know or have experienced. ${ }^{10}$

Although such findings have mainly been derived from experimental studies of classroom learning, they seem to be applicable to the educational facets of medical audit groups. Working in groups provides doctors with the opportunity to see how others work (through telling, asking, or listening) and to gauge how their own performance and views are received by their peers. ${ }^{11}$ Together these opportunities encourage the assessment of personal strengths and weaknesses, which may then lead to changes in practice. It is in group contexts that these mechanisms of presentation, comparison, and reflection can be most effectively accomplished. ${ }^{12} 13$

\section{Background}

The case studies presented here are drawn from a small observational study of a stratified sample of four of the 15 standard setting groups which met during the North of England Study of Standards and Performance

upon Tyne NE2 4AA

Accepted for publication

13 October 1992 
in General Practice. The study was designed to evaluate the effect of standard setting and other educational interventions on the process and outcome of the care of children in general practice. In all, 92 general practitioner trainers in the North of England formed into groups and were given the task of setting standards for the diagnosis and management of a range of specified conditions (for example, acute cough, itchy rash, bedwetting) in children. Subsequent examination of the records of children consulting participating doctors for one of these study conditions and the findings of surveys of the children's parents enabled the investigators to detect any changes in clinical practice which arose from standard setting. ${ }^{14} 15$ The observational subsidiary study was designed to study the process of standard setting within groups. Of the four groups observed, group 1 consisted of trainers randomly selected from participants within the same locality; group 2 was an existing trainer group created for another purpose, and groups 3 and 4 each comprised all the trainers participating from a given locality. ${ }^{14}$

An observer attended a total of 19 meetings of the four groups and tape recorded their discussions. Transcripts of the discussions were then used in a qualitative analysis of group interaction. ${ }^{16}{ }^{17}$ Since there was little prior knowledge of the workings of such groups an unstructured, exploratory approach was adopted. Box 1 records a fragment of a discussion from group 1 , whose six members were setting a clinical standard for the diagnosis and management of acute cough in children under 10 years old.

There is no simple way in which we could say whether any of these doctors learnt anything as a result of this fragment of discussion. Such fine assessments were not part of the study design. Nevertheless, the fragment does show how the group provides a forum for the presentation of a way of working (Dr A's first utterance); a request for clarification (Dr C's first utterance); (mild)

Dr A: I can't think when I last counted a respiratory rate. To me, what matters is what the particular child is like and other things such as whether they're using accessory muscles...

Dr B: . . but I mean supposing you can, we're getting . . .

Dr C: . . What would you call rapid then (uses Dr A's name)? You said "fast"

Dr B: You never measure it then?

Dr C: Yes what would you call a fast rate?

Dr A: Well, I wouldn't count it; it would be on what the appearance would be and whether the colour was all right ... whether they were using accessory muscles...

Dr C: Stick to the rate. I mean how sure are you? Is just calling it "fast" good enough? I think that's really what we're all now asking ourselves

Box 1 Fragment of discussion in group 1 about respiratory rate in children aged under 10 years with acute cough challenges (Dr B's and Dr C's second utterances); a reassertion of position (Dr A's second utterance); and, finally, a more explicit evaluation which makes reference to the group's task (Dr C's third utterance). As a result of these exchanges any or all the participants (including the four listeners) might have learnt from the others and had grounds for reflecting on "how they work." On this occasion the nature of the group process provided these opportunities; but whether or not groups always function in this enabling manner depends on several factors, ${ }^{18}$ some of which are illustrated in the following case studies selected from the three other groups observed.

\section{Case studies of group process}

CASE 1: AN IMPOSED TASK

Group 2 was an established trainer group with 11 members who met regularly to discuss vocational training and other matters of mutual concern. They saw the standard setting task as something which had to be "fitted in" to the group's existing agenda. None of the group's meetings dealt exclusively with standard setting, and the first meeting attended by the observer did not address the topic at all. When the group did begin standard setting it was not with any great enthusiasm: the observer felt that the group was happiest doing its own business. In this climate it was not surprising that the group executed its task quickly and almost perfunctorily. When members presented home produced drafts of portions of the standard (a set of diagnostic criteria for pertussis, for example) these were accepted without discussion; and when the whole task had not been completed by the end of the third meeting the group was reluctant to organise a fourth meeting. Thus what could have been a useful learning exercise was stifled by asking a pre-existing group to take on a task that came to be seen as a burden.

CASE 2: A DIFFICULT TASK

Trainer groups did not choose the conditions for which they were to set standards but had them allocated by the study organisers in the first (1983-4) and second (1985-6) rounds of standard setting. At the end of the first ("training") round all three groups working on "chronic handicap" had expressed dissatisfaction with their standards. The organisers acknowledged that this was a condition which covered too many diagnoses and involved a wide range of carers over a prolonged period and was therefore too difficult a topic for standard setting.

The nine members of group 3 had been brought together for the standard setting study because they all practised in the same area. When they came to set a standard for the second round they relived their difficulty with chronic handicap - the condition they had been allocated in the first round. At the beginning of their first meeting in 1985 the discussion focused on their previous meetings (box 2). Clearly one of the group's own 
Dr D: I think one of the things that went wrong with the ... last thing, was that it was such a nebulous task that we were given. I personally felt overwhelmed by the thing and .. I . . . found it very difficult . . .

Dr E: You feel it was the subject rather than the group?

Dr D: I felt it was the subject ... I thought that certainly towards the end ... In the latter half of what we were doing ... (pause)

Dr F: If the outcome of this is to improve your standards ... if I address myself to the question: did the work we did last year in any way alter my working with handicapped children, I'm afraid the answer must be "no" . and therefore the whole thing was a useless exercise as far as I'm concerned

Box 2 Fragment of discussion in group 3 about itchy rash in children aged under 10 years

explanations for the problems it experienced in the first round was the condition it had been allocated (although Dr E implies another explanation). It is also clear that in the opinion of one member (Dr F) this had prevented him learning anything from the task.

CASE 3: A DISRUPTIVE MEMBER

Group 4 also contained nine members who were brought together because they all practised in the same area. The third meeting of the group was the first (and only one) attended by Dr G. On looking at the notes of the previous meeting, he immediately criticised the approach adopted and proposed an alternative based on the standard set in the "training" year. Since the architect of the approach criticised was not present to defend his contribution $\mathrm{Dr} G$ did not have much difficulty in pressing his views on the meeting. His input did not altogether disrupt task achievement, but it did create a degree of tension in the group which had not been observed up to that point. Furthermore, the new approach was so like that used in the previous round that it became difficult for the group to learn from their second task. Hence, what emerged in this meeting had a direct influence on the outcome of the year's work.

CASE 4: AN OBSTRUCTIVE MEMBER

During the second meeting of group 3 one member objected to the study's preferred method of depicting a standard in the form of an algorithm. The member declared that flow charts were irrelevant to the way he practised medicine and he would not be persuaded by other group members to comply "just for the sake of the exercise." With so much effort being devoted to this issue very little progress was made for the rest of that meeting. Only three members attended the third meeting. The standard - meant to be the product of the group was eventually written by two members who merged documents that they had independently produced at home. Again, an event within one meeting seemed to have a negative effect on subsequent meetings and, presumably, on the educational experience of most members of the group.

\section{Discussion}

The aim of this paper has been to identify factors influencing the functioning of standard setting groups and to assess how far it affected the achievement of the educational objectives of a major study of performance in general practice. The assessment cannot be precise since the educational objectives of the larger study were not defined in terms of learning outcomes. The main question to be investigated was the effect of setting a standard - seen as an educational intervention - on doctors' subsequent clinical practice and the health of patients. Measured in this way, the study's educational objectives were achieved. Trainers who set a clinical standard changed their prescribing patterns in directions consistent with those standards and maintained the changes for up to two years. ${ }^{14}$

If educational objectives are defined in terms of group process rather than medical outcomes, however, a different view emerges. Education then becomes a quality of experience to be evaluated according to other criteria. Educational evaluation of setting a standard in a small group might ask questions such as whether the group work enabled members to learn how other doctors work, to express their own views on the diagnosis and management of certain conditions, to gauge how those views were received by peers, and to reflect on all those things. Four case studies have been used to address such evaluative questions. The main conclusion is that there were features of the structure and functioning of the standard setting groups which influenced the educational experience of their members. In case 1 the structure of the main study had imposed a task on the group and this came to be resented, and in case 2 the task itself had an influence on how the group performed; cases 3 and 4 both identified influences which emerged once the group had started to function.

A useful framework for analysing group processes has been proposed by Krech et al (figure). ${ }^{19}$ Their model enables conceptual links to be made between the "givens" of a group (for example, the structure of the group as in case 1 or the task as in case 2), its "emergent processes" (for example, individuals' approach to the task or the group (cases 3 and 4), and the "outcomes" of group interaction (for example, whether learning takes place). The model has affinities with Donabedian's "structure-process-outcome" scheme for analysing quality assurance in health care. ${ }^{20}$

In the case studies reported here two types of influence were observed: in cases 1 and 2 the givens of the group influenced how it functioned, and in cases 3 and 4 emergent processes (in particular the behaviour of individual members) had an effect on outcomes. Both types of influence made it difficult for members to discuss matters constructively, to work together effectively, or to achieve their task. These are problems familiar to observers of groups in other contexts, such as education and social work. ${ }^{21}$ 

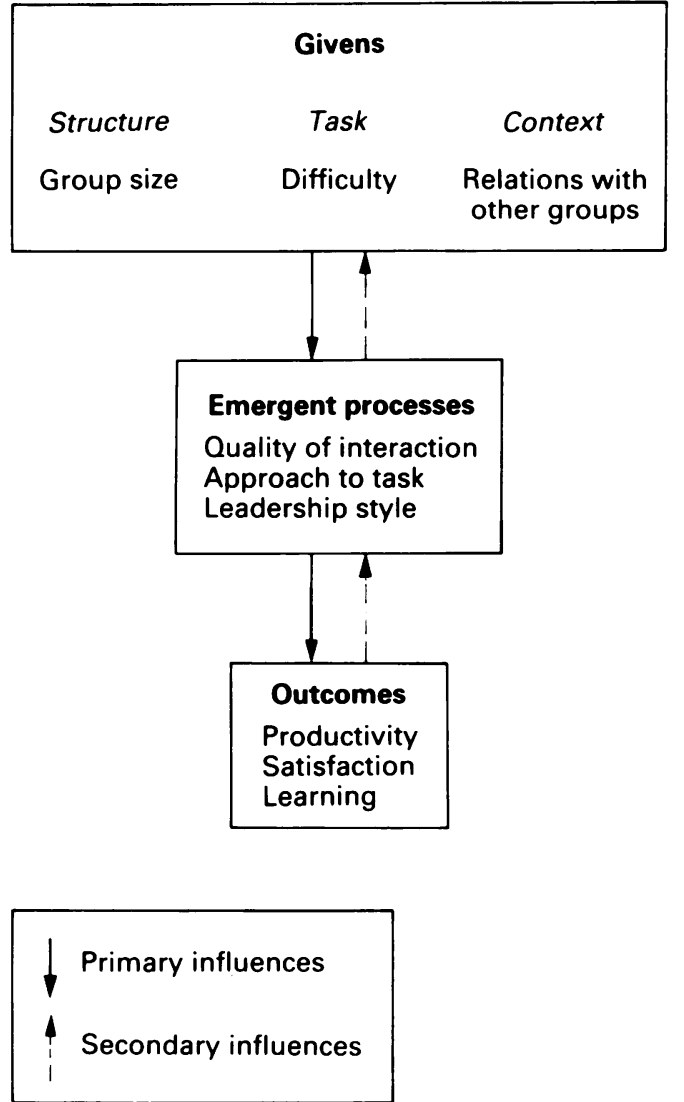

Framework for analysing group process (from Krech et $\mathrm{al}^{19}$ )

If medical audit continues to be a group centred activity these problems will have to be managed. Doctors taking part in collaborative audit projects should therefore have some appreciation of the skills needed to facilitate meetings and groups. ${ }^{22}$ Leadership skills are of primary importance since most groups need someone to create and sustain an agreed view of the task at hand and an acceptable way of working together. It is not essential for these functions to be the sole responsibility of one person: the most effective groups are those where everyone feels committed to the task and to the wellbeing of the group. Communication skills are equally important. Doctors are usually well trained in communicating with patients but are less used to, and therefore less accomplished in, communicating with colleagues, particularly in group situations. Once again, this is an aspect where each group member has to recognise a personal responsibility.

The skills required to manage conflict and resolve problems in groups are closely akin to those entailed in medical diagnosis. Firstly, problems - or the symptoms of problems need to be recognised and interpreted within an understanding of how groups work. Secondly, the cause(s) of the problem need to be identified. Thirdly, a member of the group (not necessarily the leader) needs to make an effective intervention. Such skills usually have to be learnt in the context of actual group experience. In groups with a facilitator, which is increasingly the case for audit activities, this task is much simplified; otherwise groups have to cultivate a critical attitude towards their own activities. Without an awareness of these group working skills ${ }^{23} 24$ audit groups will find their educational role frequently hindered by the kinds of interactional difficulties illustrated in this paper.

The North of England Study of Standards and Performance in General Practice was funded by the Department of Health, and the observational study was funded by the Royal College of General Practitioners. We thank the members of groups 1-4 for agreeing to their discussions being observed and recorded, Cam Donaldson and Paula Davis for their help in data collection and analysis, and Sylvia Hudson for secretarial help in preparing this paper.

Royal College of Physicians. Medical audit. London: RCP, 1989.

2 Royal College of Surgeons of England. Guidelines to clinical audit in surgical practice. London: RCS, 1989.

Batstone GF. Educational aspects of medical audit. $B M F$ 1990;301:326-8.

4 Coles N. Making audit truly educational. Postgrad Med $\mathcal{F}$ 1990;66(suppl 3):532-6.

5 Scott M, Marinker ML. Small group work. In: Marinker ML, ed. Medical audit and general practice. London: BMJ, ML, ed. Medical

6 Pickering G. Quest for excellence in medical education. Oxford: Oxford University Press, 1978.

7 Ruddock J. Learning through small group discussion. London: Society for Research into Higher Education, 1978.

8 Hull SA. Why run a group? BMf 1984;228:1811-2.

Webb NM. Peer interaction and learning in small groups. International fournal of Educational Research 1989;13:21-39.

10 Moust JHC, Schmidt HG, De Volder ML, Belien JJ, De Grave WS. Effects of verbal participation in small group Grave WS. Efrects of verbal partipation in small group MW, Warren PD, eds. Student learning: research in education and cognitive and psychology. Milton Keynes: Open University Press, 1987:147-54.

11 Hughes J, Humphrey C. Medical audit in general practice. London: King's Fund Centre, 1990

12 Schön DA. The reflective practitioner. London: Temple Smith, 1983.

13 Samuel O. How doctors learn in a Balint group. Fam Pract 1989;6:108-13.

14 North of England Study of Standards and Performance in General Practice. Medical audit in practice. I. Effects on doctors' clinical behaviour for common childhood conditions. BMF 1992;304:1480-4.

15 North of England Study of Standards and Performance in General Practice. Medical audit in practice. II. Effects on health of patients with common childhood conditions. health of patients with

16 Miles MB, Huberman AM. Qualitative data analysis. London: Sage, 1984.

17 Strauss AL, Corbin J. Basics of qualitative research: grounded theory procedures and techniques. London: Sage, 1990.

18 Levine JM, Moreland RL. Progess in small group research. Annual Review of Psychology 1990;41:585-643.

19 Krech D, Crutchfield RS, Ballachey EL. Individual in society. New York: McGraw Hill, 1962.

20 Donabedian A. Evaluating the quality of medical care. Milbank Memorial Fund Quarterly 1966;44:166-203.

21 Douglas T. A handbook of common groupwork problems. London: Routledge, 1991.

22 Westley F, Waters JA. Group facilitation skills for managers. Management Education and Development 1988;19:134-43.

23 Adair J. Effective teambuilding. London: Gower, 1986

24 Larson C, La Fasto F. Team work. London: Sage, 1989. 